\title{
Methane-Air Plasma-Assisted Ignition Excited by Nanosecond Repetitively Pulsed Discharge: Numerical Modeling and Effect of Inert Gas
}

\author{
Chengjie Bai, ${ }^{\#}$ Shi Li,, Tong Chen," Xiaoxiao Chen, Wenjing Meng, and Jie Pan* \\ Cite This: ACS Omega 2021, 6, 24156-24165 \\ Read Online
}

ABSTRACT: Plasma-assisted ignition and combustion are promising approaches for controlling ignition enhancement and flame stabilization. The global loosely coupled plasma-assisted combustion kinetic model has been established by combining the ZDPlasKin and ChemKin codes, which is employed to numerically investigate the effects of the inert gas-diluted methane-air nanosecond repetitively pulsed (NRP) plasma on the ignition process. The results indicate that addition of the inert gas is conducive to increasing the chemical reactive species densities in the methane-air NRP discharge plasma. The addition of inert

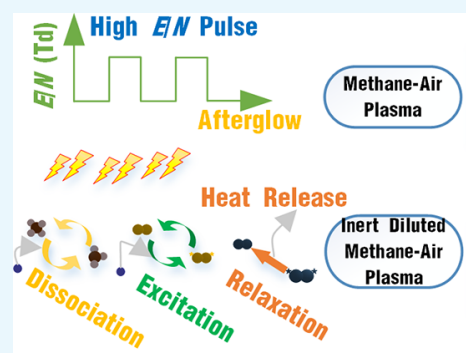

- 0 - $\bullet$ H

e $\bullet \mathrm{N} \bullet \mathrm{He}$

- Ar $\star$ Excited Species

Ignition Delay $(\mu \mathbf{s})$ gases affects the generation pathways of plasma species and their corresponding contribution rates. Compared with the methane-air plasma, the dilution of inert gases shows obvious effects on reducing ignition delays, and the dilution of He and Ar decreases the ignition delays by 58.0 and $84.0 \%$, respectively. $\mathrm{CH}_{3}+\mathrm{O}_{2}=\mathrm{CH}_{3} \mathrm{O}+\mathrm{O}$ and $\mathrm{H}+\mathrm{O}_{2}=\mathrm{O}+\mathrm{OH}$ are the dominant conducive reactions in the methane-air ignition chemistry. Moreover, the dilution of inert gases has considerable influences on the normalization sensitivity coefficients, especially for the reaction of $\mathrm{H}+\mathrm{O}_{2}=\mathrm{O}+\mathrm{OH}$.

\section{INTRODUCTION}

Energy crisis and environmental pollution are the two principal factors that affect the development of human society. ${ }^{1-3}$ Replacing fossil fuels with renewable resources and optimizing the combustion process with advanced technology are imperative ways to relieve the energy crisis and reduce the pollution. Methane, serving as the simplest and fairly abundant green organic solvent, has been considered an essential energy resource of industrial chemicals. ${ }^{4,5}$ In addition, the contents of aldehydes and polycyclic aromatic hydrocarbons in the methane combustion product are extremely few. Attributed to the high hydrogen-to-carbon ratio of methane, the generation of carbon dioxide during the methane combustion process is far less compared to other fuels, which can effectively alleviate the greenhouse effect caused by carbon dioxide emission. ${ }^{6}$ However, in terms of its physical and chemical properties, methane has a particular tetrahedral molecular structure that requires a high energy to break the carbonhydrogen bonds in the combustion reaction process. Nonequilibrium discharge plasma is able to convert methane into value-added chemical reactive components, such as ions, radicals, and excited species. ${ }^{7-12}$ Therefore, plasma-assisted ignition (PAI) and plasma-assisted combustion (PAC) are turning into promising ways to improve fuel oxidation and combustion efficiency prominently.

Discharge plasma excitation approaches, such as gliding $\operatorname{arc}^{13}$ alternating current, ${ }^{14}$ direct current, ${ }^{15}$ radiofrequency, ${ }^{16}$ microwave, ${ }^{17}$ and dielectric barrier discharge, ${ }^{18}$ have been implemented to achieve PAI and PAC. In comparison with these methods, nanosecond repetitively pulsed (NRP) discharge could provide higher power density and high reduced electric field $(E / N)$ to accelerate the energetic electron-generating uniform plasma as well as various chemical reactive components for effective fuel oxidation and significant ignition enhancement. Lefkowitz et al. have studied the effectiveness of methane-air mixture NRP discharge plasma in reducing the ignition time both in a flow tube and a pulsed detonation engine (PDE) by in situ and real-time diagnoses, proving that the visual flame development time and PDE ignition time of NRP discharge are distinctly reduced in the comparison with the conventional spark ignition time under the different equivalence ratios and discharge parameters. ${ }^{19}$ Cont-Bernard et al. have investigated the chemical effect of methane-air NRP glow discharge on laminar flame using the same diagnosis technology, reporting that $\mathrm{OH}$ and $\mathrm{CH}$ fluorescence intensities in the flame increased by up to 40 and $10 \%$ under the actuation of plasma compared to the base

Received: July 13, 2021

Published: September 8, 2021 

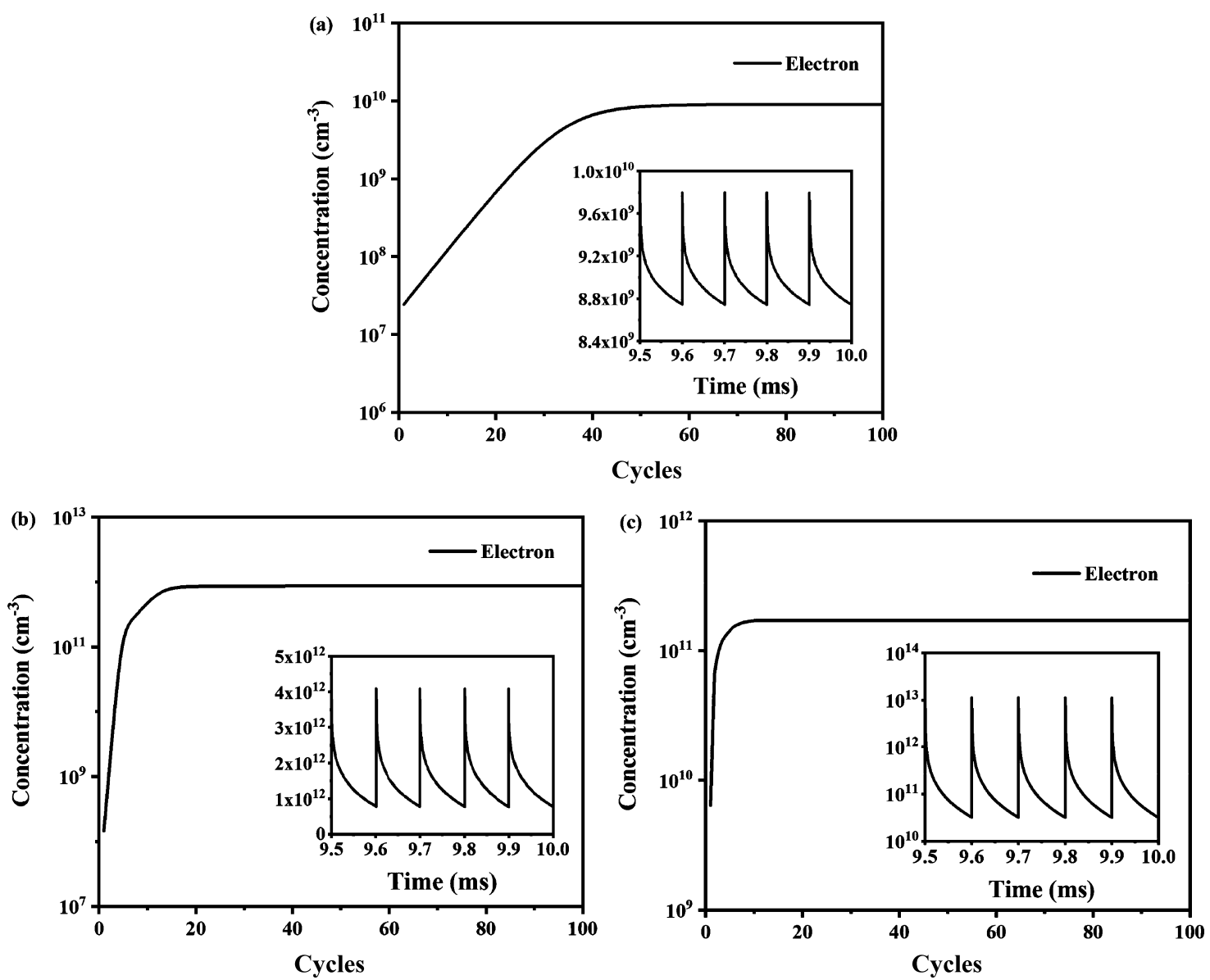

Figure 1. Electron density temporal evolutions of (a) methane-air plasma, (b) He-diluted methane-air plasma, and (c) Ar-diluted methane-air plasma.

flame, respectively. ${ }^{20}$ Because the experimental implementation of PAI and PAC in special environments still has certain limitations, numerical simulation has become a preferred approach to deeply explore the temporal and spatial evolution characteristics and the chemical dynamics of PAI and PAC. Models such as one-dimensional fluid models, ${ }^{18}$ one-dimensional particle-in-cell Monte Carlo collision models, ${ }^{21}$ and global models ${ }^{22}$ are the extensively used methods to investigate PAI and PAC. Casey et al. have explored the effect of the nanosecond pulsed applied voltage on ignition utilizing a twofluid solver, discovering that the recombination of the fuel and the oxidant fragments increases the content of $\mathrm{OH}$ in the front of the outwardly propagating flame and accelerates the consumption of fuel. ${ }^{23}$ Overall, the NRP discharge plasma has been widely used to achieve uniform and controllable combustion with low energy consumption in the processes of PAI and PAC.

The traditional simulation methods focus on the loosely coupled plasma model and combustion model, which make the plasma kinetic mechanisms combined with the combustion kinetic mechanisms by adding a slight amount of the known plasma species generated via gas discharge and the interaction model related to the combustion kinetic mechanisms into combustion model. ${ }^{22,24,25}$ In addition, due to the complexity of the discharge, coupling includes not only the integration of its own various effects but also the combination between plasma and combustion, which makes simulation considerably difficult. Predicting the species derived from plasma and the spatial and temporal distribution characteristics to select the key chemical kinetic model has essential impacts on the success and the credibility of the simulation. Therefore, the core tasks of this study are (1) to establish a systematic zerodimensional loosely coupled model for PAI, (2) to explore the potential chemical reaction mechanisms, and (3) to analyze key characteristics such as species temporal distributions and chemical reaction pathways.

In the methane-air plasma, the dilution of different inert gases could contribute to the change of the electron energy distribution function, and the energy loss fractions could lead to electron energy deposition into different molecular degrees of freedom. As a consequence, a considerable impact on the yields of discharge products and the rates of combustion processes could be observed. However, the influence of different inert gas diluents on the gas discharge and the fuel oxidation of methane-air plasma has not been fully taken into account. Toward this point, it is vital to explore the effect of the inert gas diluents on the physicochemical mechanisms of methane-air plasma and enhance the fuel oxidation efficiency.

Investigations on the effects of different inert gas dilutions on the combustion processes have been conducted, which illustrates that the dilution of inert gas has distinctive influences on the energy deposition and the kinetic coefficient of methane-air plasma in the ignition process. ${ }^{26-32}$ In addition, $\mathrm{Yi}$ et al. have indicated that different diluent concentrations have a significant impact on the flame structure and the soot flame temperature. ${ }^{27}$ Mohammad et al. have 

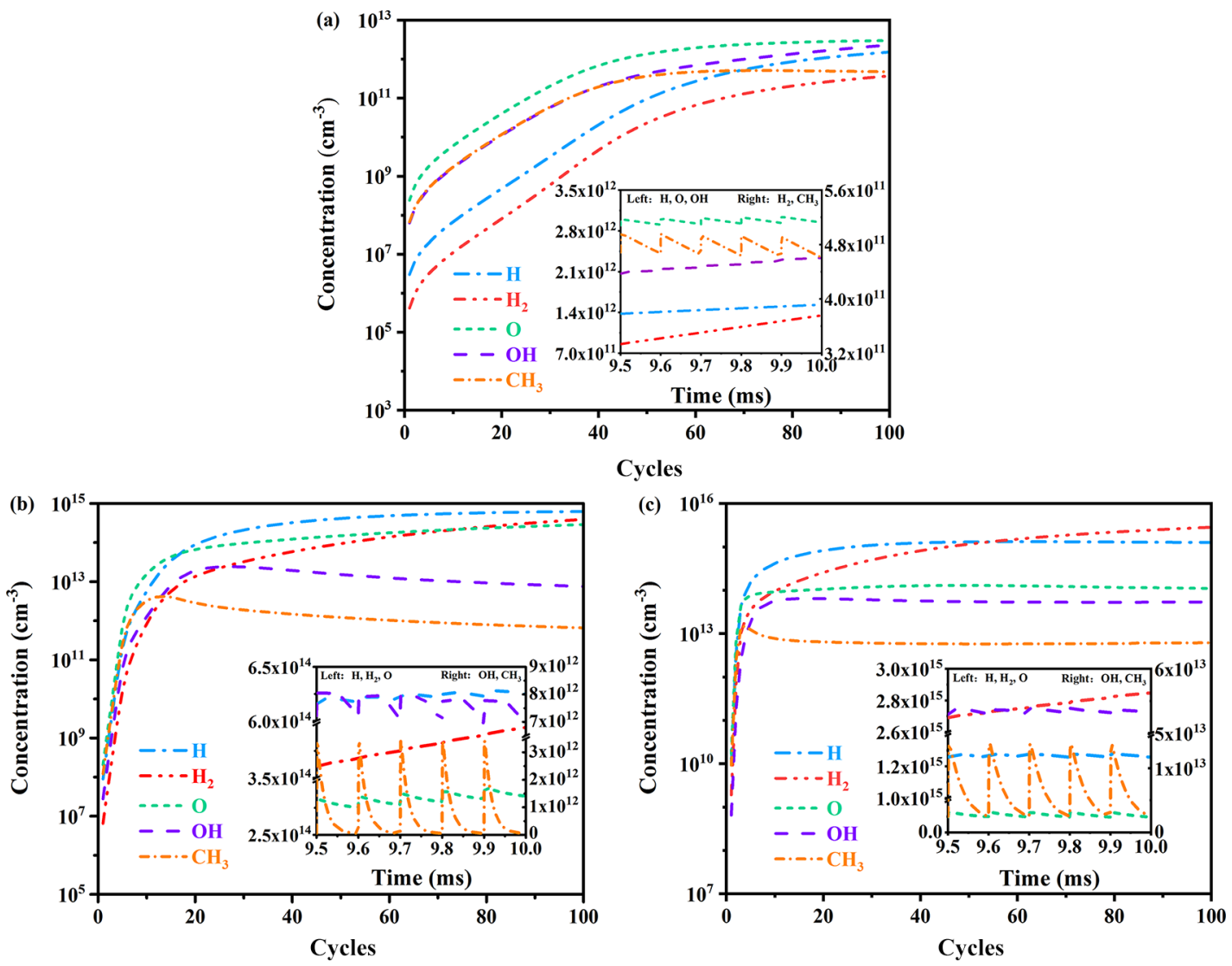

Figure 2. Radical density temporal evolutions of (a) methane-air plasma, (b) He-diluted methane-air plasma, and (c) Ar-diluted methane-air plasma.

proved that the burning velocity decreases with the increase in percentage of inert gas. ${ }^{28} \mathrm{Li}$ et al. have explored the impact of parameters such as inert dilution and preheating temperature on the combustion, revealing that compared with the inert dilution only preheating temperature can influence the flame extinction. ${ }^{29}$ Moreover, $\mathrm{Ar}$ and $\mathrm{He}$ are suitable feed gases for the research of the effect of inert gas dilution on the methaneair PAI due to their easy acquisition and low cost. Sun et al. and Liu et al. have conducted studies on combustion characteristics, the results of which showed that the addition of inert gases like $\mathrm{N}_{2} / \mathrm{CO}_{2}$ or Ar to the fuel mixture can appropriately control the flame temperature and the species generated from He-diluted fuel has lower oxidation reactivity. ${ }^{30,31}$ Zhang et al. have pointed out that the dilution of Ar not only can keep the cycle-by-cycle variations of the tested engine unchanged but also is beneficial for the mean effective pressure. $^{32}$ Since the inert gas dilution has significant influences on the PAC and $\mathrm{Ar}$ and $\mathrm{He}$ are the general and appropriate inert gases, the present study takes the inert gases $\mathrm{Ar}$ and $\mathrm{He}$ into account.

The present study establishes a global loosely coupled chemical kinetic model to investigate the impact of the inert gas-diluted methane-air NRP discharge plasma on ignition enhancement. The dilution ratio between the inert gas and the methane-air is $2: 8$, which is consistent with the literature. ${ }^{26}$ The rest of this study is organized as follows. The effects of the inert gas on the species density, the reaction pathway, and the ignition enhancement are systematically calculated and investigated in Section 2. Section 3 gives the summarized conclusions. Finally, the numerical modeling of PAI is introduced in Section 4.

\section{RESULTS AND DISCUSSION}

2.1. Effect of Inert Gas on Species Density. In this section, the average density of electrons, neutral radicals, shortlife electronically excited species, and $\mathrm{O}_{2}$ electronically excited states in the first 100 periods and the instantaneous density of these species in the last five periods of the inert gas-diluted methane-air plasma are compared and discussed.

Figure 1 shows the temporal evolutions of the average density of electrons in the first 100 periods and the instantaneous density of electrons in the last five periods of methane-air plasma, He-diluted methane-air plasma, and Ardiluted methane-air plasma. It can be seen that the average electron density of the He-diluted methane-air plasma is the highest followed by the Ar-diluted methane-air plasma. The distinction of the three gas component plasma should be attributed to the electron collision cross section in the processes of electron impact ionization and electron impact dissociation. In addition, the instantaneous electron density of Ar-diluted methane-air plasma is much higher than the instantaneous electron densities of the He-diluted methaneair plasma and the methane-air plasma. Moreover, the average electron density presents the equilibrium state after a rapid growth in the first several periods, and the Ar-diluted methane-air NRP discharge plasma reaches the equilibrium position preceding the other gas components. The temporal evolution of the instantaneous electron density in the singlepulsed period shows that electrons are excited efficiently in the 

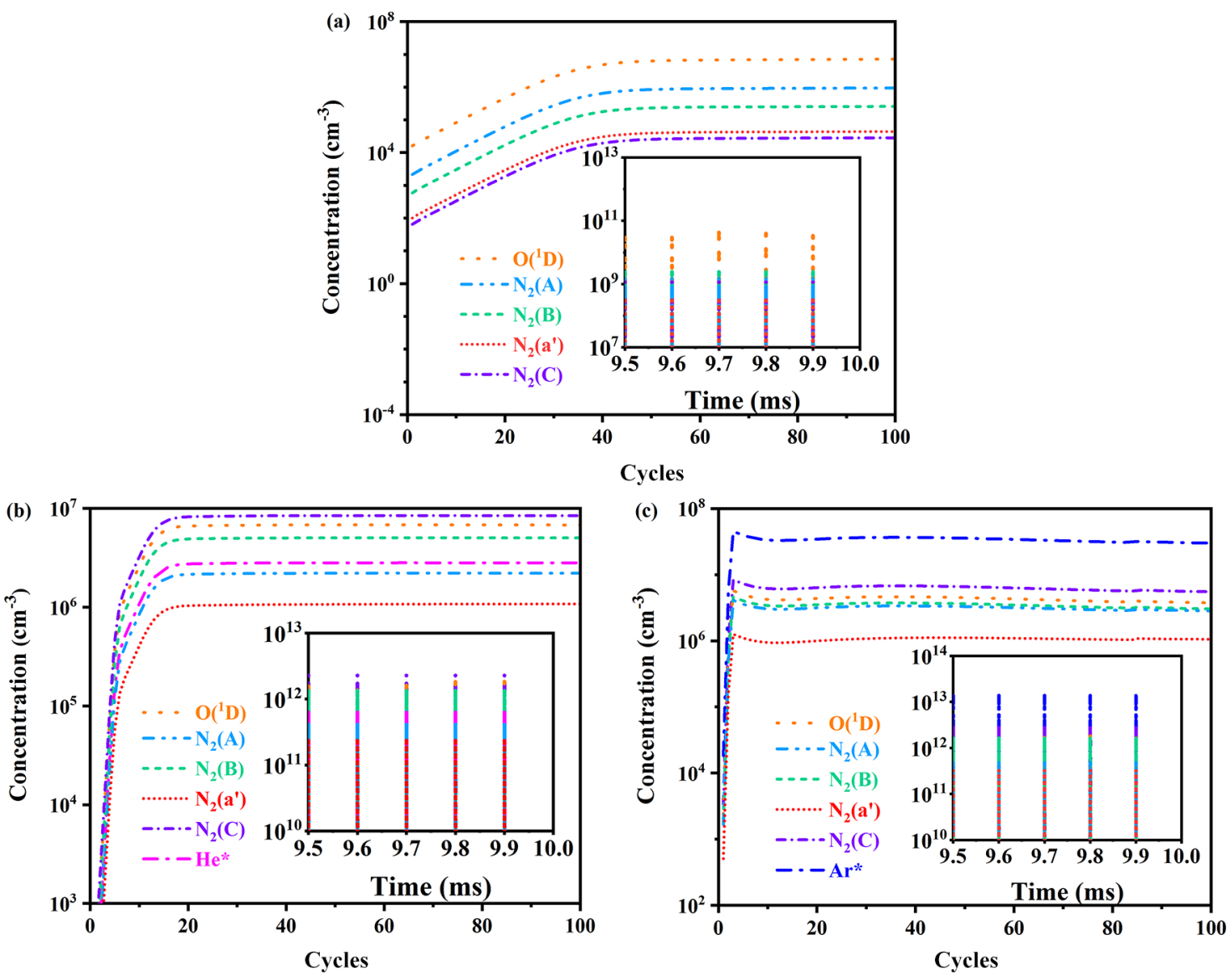

Figure 3. Electronically excited species temporal evolutions of (a) methane-air plasma, (b) He-diluted methane-air plasma, and (c) Ar-diluted methane-air plasma.

initial stage of the pulse discharge and quenched rapidly in the afterglow stage.

Figure 2 shows the temporal evolutions of the average radical densities in the first 100 periods and the instantaneous densities in the last five periods involving methane-air plasma, He-diluted methane-air plasma, and Ar-diluted methane-air plasma. Radicals such as $\mathrm{H}, \mathrm{H}_{2}, \mathrm{O}, \mathrm{OH}$, and $\mathrm{CH}_{3}$ are long-life species and their average radical densities rapidly increase and then slowly increase or approximately reach equilibrium. Comparing with Figure 1, the temporal evolution of the average radical densities is similar to those of electrons under three different gas components. The average radical densities, which are improved by two and three orders of magnitude by the addition of $\mathrm{Ar}$ and $\mathrm{He}$, are less than $10^{13} \mathrm{~cm}^{-3}$ in the methane-air plasma. In addition, the gas component can also affect the proportion of the different radicals. Post the 100 pulse periods, the contents of $\mathrm{O}$ in the methane-air plasma, $\mathrm{H}$ in He-diluted methane-air plasma, and $\mathrm{H}_{2}$ in the Ar-diluted methane-air plasma are the highest ones, respectively. This is related to the time when the average densities reach the equilibrium state under three different gas components. The proportions of radicals reach stabilization before 100 periods in the Ar-diluted methane-air plasma, while in the other plasma, the proportions of radicals change continuously at the 100th period and gradually approach that of the Ar-diluted methane-air plasma species. Furthermore, the growth rates of the average radical densities in the Ar-diluted methane-air plasma are faster in the first five periods compared with the growth rates of the average radical densities in the He-diluted methane-air plasma and the methane-air plasma.

Figure 3 shows the temporal evolutions of the average shortlife electronically excited species density in the first 100 periods and the instantaneous density in the last five periods of methane-air plasma, He-diluted methane-air plasma, and Ardiluted methane-air plasma. The results illustrate that the average densities of the short-life electronically excited species are several orders of magnitude lower than those of the electrons and the radicals. The addition of the inert gas has little effect on the average species densities, which should be put down to the fact that the short-life electronically excited species are generated effectively by electron impact excitation reactions in the high voltage pulse duration and they might be consumed or even disappear with the heat release through substantial numbers of the relaxation reactions in the afterglow stage. However, the addition of $\mathrm{Ar}$ and $\mathrm{He}$ has a vital impact on the instantaneous density of the short-life electronically excited species, which increases by two or three orders of magnitude.

Figure 4 shows the temporal evolutions of the average density of $\mathrm{O}_{2}$ electronically excited species in the first 100 periods and the instantaneous density in the last five periods of methane-air plasma, He-diluted methane-air plasma, and Ardiluted methane-air plasma. The addition of inert gas to the methane-air plasma has almost no effect on the average density of $\mathrm{O}_{2}\left(\mathrm{a}^{1} \Delta_{\mathrm{g}}\right)$ with less than one order of magnitude improvement, but it has a great effect on the $\mathrm{O}_{2}\left(\mathrm{~b}^{1} \Sigma_{\mathrm{g}}^{+}\right)$ average density with two orders of magnitude enhancement. 

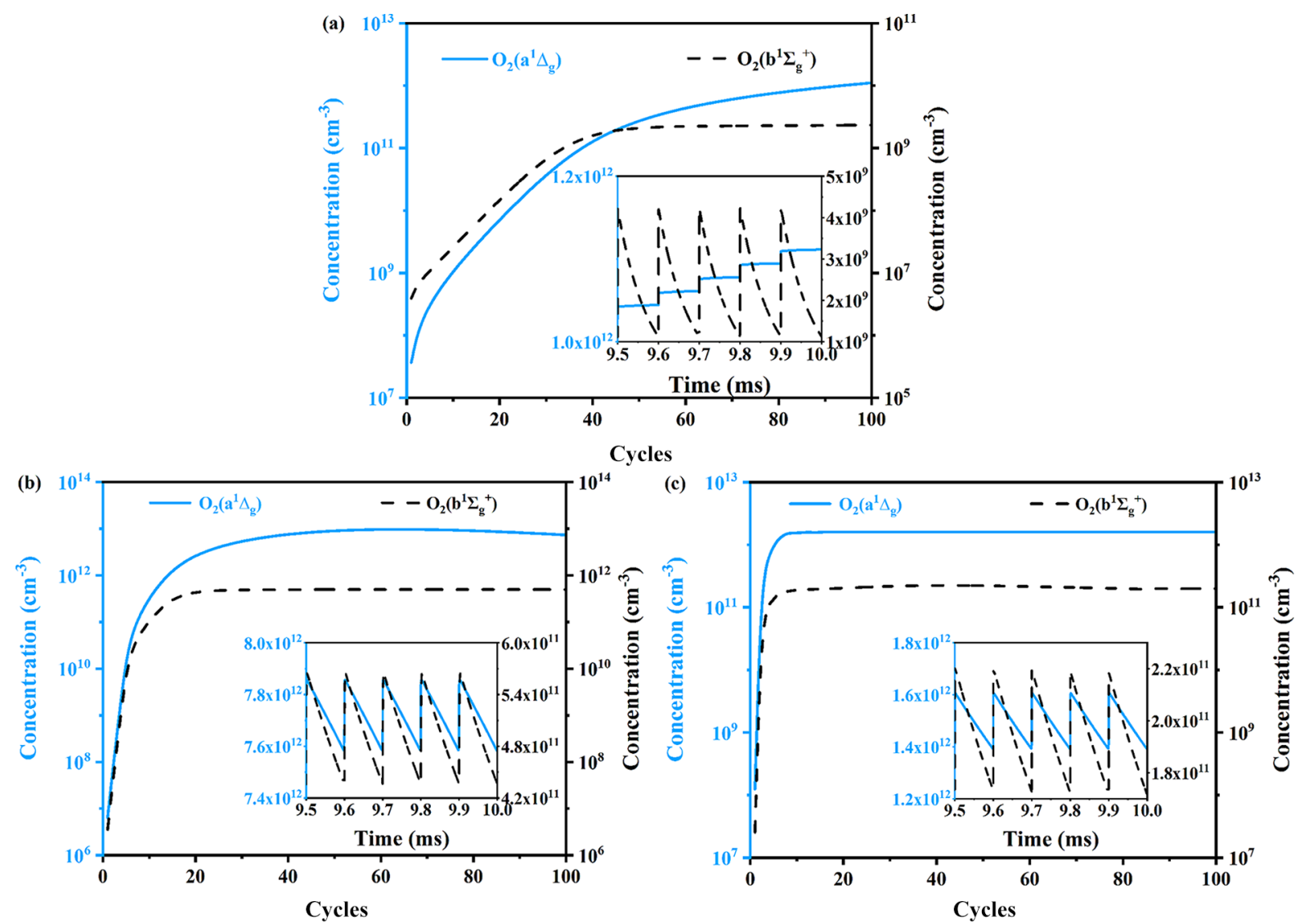

Figure 4. $\mathrm{O}_{2}\left(\mathrm{a}^{1} \Delta_{\mathrm{g}}\right)$ and $\mathrm{O}_{2}\left(\mathrm{~b}^{1} \Sigma_{\mathrm{g}}^{+}\right)$density temporal evolutions of (a) methane-air plasma, (b) He-diluted methane-air plasma, and (c) Ar-diluted methane-air plasma.

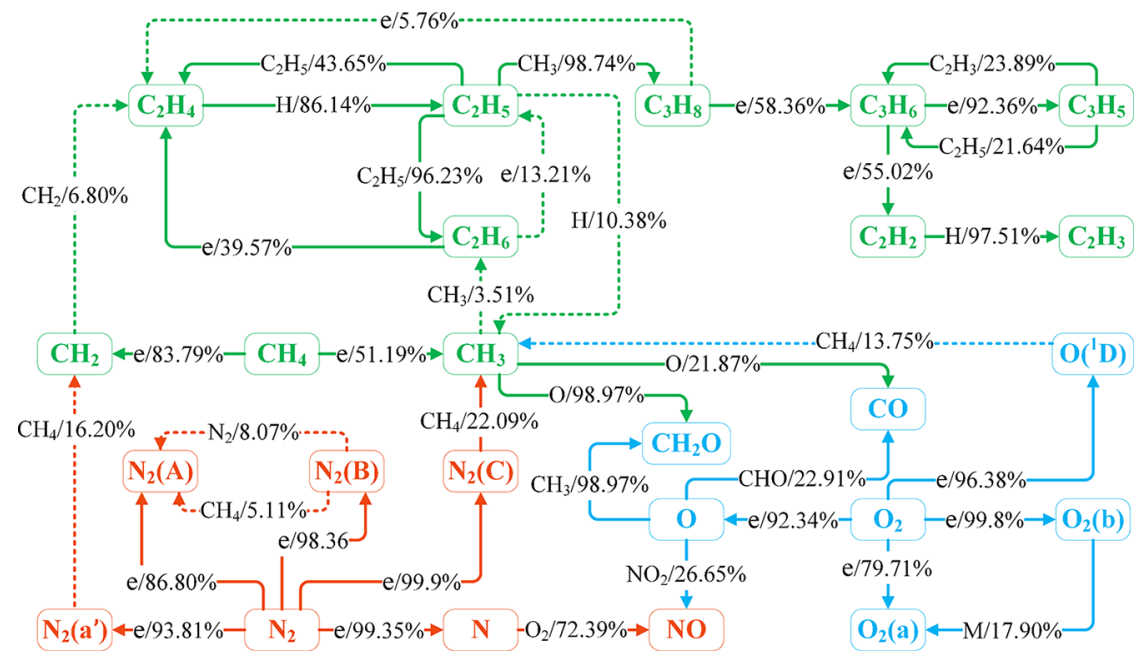

Figure 5. Reaction pathways of the methane-air NRP discharge plasma. The solid line and dashed line represent the primary reaction pathways with the reaction contribution rate not less than $20 \%$ and the secondary reaction pathways with the reaction contribution rate less than $20 \%$, respectively. The reaction pathways of $\mathrm{CH}_{4}, \mathrm{~N}_{2}$, and $\mathrm{O}_{2}$ are denoted by green line, red line, and blue line. Other species involved in the reactions and the reaction contributions to produce these species are shown in the middle of the line.

This difference could be attributed to the fact that $\mathrm{O}_{2}\left(\mathrm{a}^{1} \Delta_{\mathrm{g}}\right)$ is mainly generated by electron impact excitation and the transition of $\mathrm{O}_{2}\left(\mathrm{~b}^{1} \Sigma_{\mathrm{g}}^{+}\right)$, and $\mathrm{O}_{2}\left(\mathrm{~b}^{1} \Sigma_{\mathrm{g}}^{+}\right)$is mainly produced by the electron impact excitation, which will be analyzed in Section 2.2. Moreover, the temporal evolution of the average density of the electronically excited species of $\mathrm{O}_{2}$ is consistent with that of the electrons, which indicates that the increase of the species density mainly depends on the changing of the electron density caused by the electron impact excitation reactions in the inert gas-diluted methane-air plasma.

2.2. Effect of Inert Gas on the Reaction Pathway. In order to further investigate the main sources of critical species and the effect of inert gas in the methane-air NRP discharge plasma, the product of the reactant species densities and the reaction rate coefficient is used to calculate the specific species 

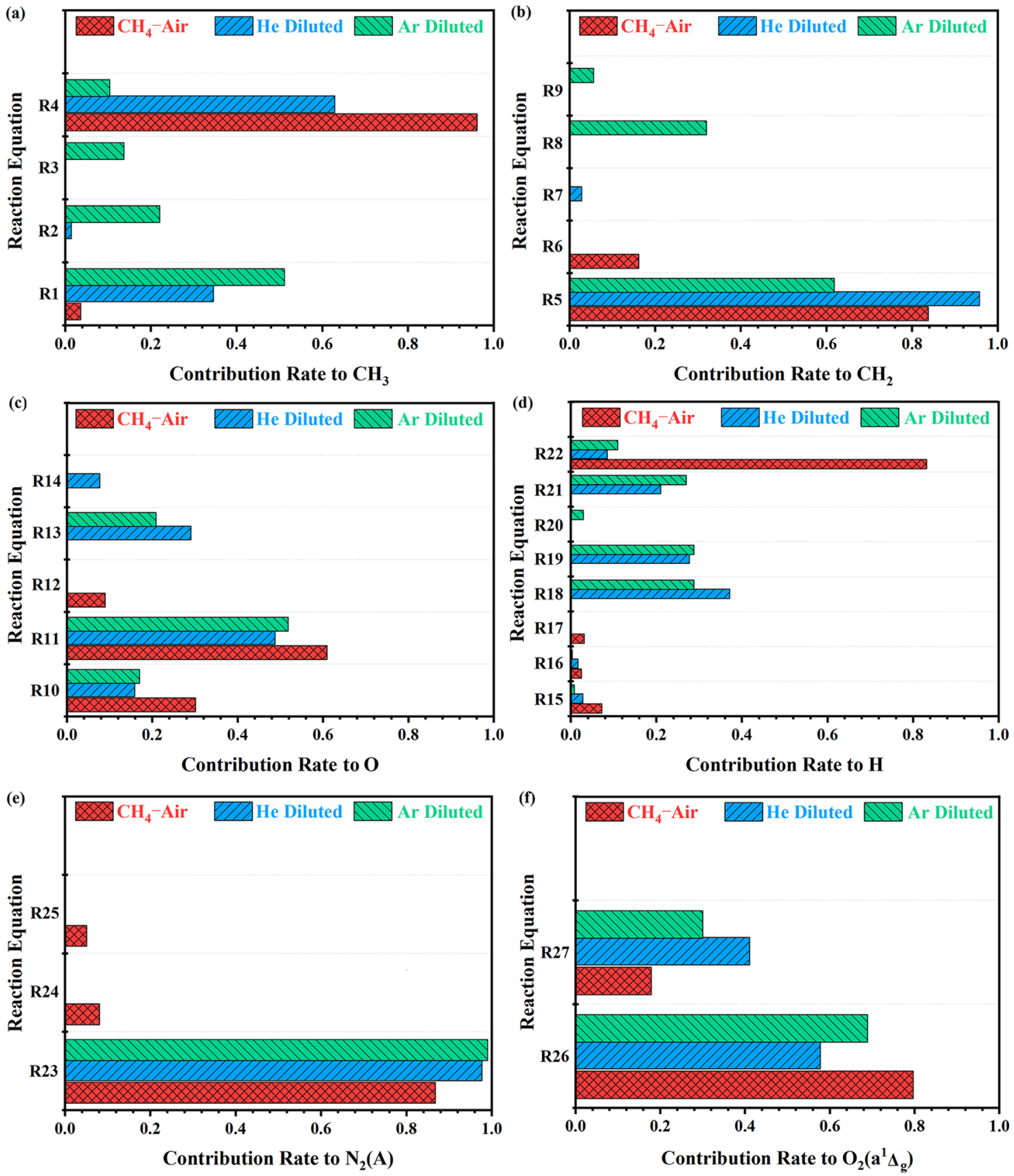

Figure 6. Effects of chemical reactions on species generation paths and generation rates for (a) $\mathrm{CH}_{3},\left(\right.$ b) $\mathrm{CH}_{2},(\mathrm{c}) \mathrm{O},(\mathrm{d}) \mathrm{H},(\mathrm{e}) \mathrm{N}_{2}(\mathrm{~A})$, and (f) $\mathrm{O}_{2}\left(\mathrm{a}^{1} \Delta_{\mathrm{g}}\right)$.

contribution rate of each reaction. The reaction pathway is determined to explain the whole reaction system.

Figure 5 shows the reaction pathways for the generation of different kinds of species in the methane-air NRP discharge plasma. The solid line and dashed line represent the primary reaction pathways with the reaction contribution rate not less than $20 \%$ and the secondary reaction pathways with the reaction contribution rate less than $20 \%$, respectively. The consumption and generation pathways of $\mathrm{CH}_{4}, \mathrm{~N}_{2}$, and $\mathrm{O}_{2}$ are denoted by green line, red line, and blue line. Other species involved in the reactions and the contribution of the reaction to produce these species are shown in the middle of the line.

It can be seen that $\mathrm{CH}_{3}$ plays an essential role in the formation of hydrocarbons $\mathrm{C}_{x} \mathrm{H}_{y}(x \leq 3), \mathrm{CH}_{2} \mathrm{O}$, and $\mathrm{CO}$ in the methane-air NRP discharge plasma. The majority of $\mathrm{CH}_{3}$ derives from the electron impact dissociation reactions of $\mathrm{CH}_{4}$, the reaction between $\mathrm{N}_{2}(\mathrm{C})$ and $\mathrm{CH}_{4}$, the reaction between $\mathrm{O}\left({ }^{1} \mathrm{D}\right)$ and $\mathrm{CH}_{4}$, and the recombination reaction between $\mathrm{C}_{2} \mathrm{H}_{5}$ and $\mathrm{H}$. $83.79 \%$ of $\mathrm{CH}_{2}$ is induced by the electron impact dissociation reactions of $\mathrm{CH}_{4}$. More than $90 \%$ of the electronically excited species of $\mathrm{N}_{2}$ originates from the electron impact excitation reaction of $\mathrm{N}_{2}$ except $\mathrm{N}_{2}(\mathrm{~A}) \cdot 79.71 \%$ of $\mathrm{O}_{2}\left(\mathrm{a}^{1} \Delta_{\mathrm{g}}\right)$ comes from the electron impact excitation of $\mathrm{O}_{2}$, and additional $17.9 \%$ stems from the reactions related to $\mathrm{O}_{2}\left(\mathrm{~b}^{1} \Sigma_{\mathrm{g}}^{+}\right)$. The vast majority of $\mathrm{O}_{2}\left(\mathrm{~b}^{1} \Sigma_{\mathrm{g}}^{+}\right)$derives from the electron impact excitation of $\mathrm{O}_{2}$.

Figure 6 shows the effects of chemical reactions on $\mathrm{CH}_{3}$, $\mathrm{CH}_{2}, \mathrm{O}, \mathrm{H}, \mathrm{N}_{2}(\mathrm{~A})$, and $\mathrm{O}_{2}\left(\mathrm{a}^{1} \Delta_{\mathrm{g}}\right)$ generation paths and generation rates under three gas components. The relevant 
reactions in the NRP discharge plasma kinetic model discussed in this section are listed in Table 1.

Table 1. Reactions of the NRP Discharge Plasma Kinetic Model Discussed in Section 2.2

\begin{tabular}{|c|c|}
\hline reaction number & reaction equation \\
\hline $\mathrm{R} 1$ & $\mathrm{e}^{-}+\mathrm{CH}_{4}=\mathrm{e}^{-}+\mathrm{CH}_{3}+\mathrm{H}$ \\
\hline $\mathrm{R} 2$ & $\mathrm{~N}_{2}(\mathrm{C})+\mathrm{CH}_{4}=\mathrm{N}_{2}+\mathrm{CH}_{3}+\mathrm{H}$ \\
\hline $\mathrm{R} 3$ & $\mathrm{O}\left({ }^{1} \mathrm{D}\right)+\mathrm{CH}_{4}=\mathrm{CH}_{3}+\mathrm{OH}$ \\
\hline R4 & $\mathrm{C}_{2} \mathrm{H}_{5}+\mathrm{H}=\mathrm{CH}_{3}+\mathrm{CH}_{3}$ \\
\hline R5 & $\mathrm{e}^{-}+\mathrm{CH}_{4}=\mathrm{e}^{-}+\mathrm{CH}_{2}+\mathrm{H}_{2}$ \\
\hline R6 & $\mathrm{N}_{2}\left(\mathrm{a}^{\prime}\right)+\mathrm{CH}_{4}=\mathrm{N}_{2}+\mathrm{CH}_{2}+\mathrm{H}_{2}$ \\
\hline R7 & $\mathrm{He}^{*}+\mathrm{CH}_{4}=\mathrm{He}+\mathrm{CH}_{2}+\mathrm{H}_{2}$ \\
\hline R8 & $\mathrm{Ar}^{*}+\mathrm{CH}_{4}=\mathrm{Ar}+\mathrm{CH}_{2}+\mathrm{H}+\mathrm{H}$ \\
\hline R9 & $\mathrm{Ar}^{*}+\mathrm{CH}_{4}=\mathrm{Ar}+\mathrm{CH}_{2}+\mathrm{H}_{2}$ \\
\hline $\mathrm{R} 10$ & $\mathrm{e}^{-}+\mathrm{O}_{2}=\mathrm{e}^{-}+\mathrm{O}+\mathrm{O}$ \\
\hline $\mathrm{R} 11$ & $\mathrm{e}^{-}+\mathrm{O}_{2}=\mathrm{e}^{-}+\mathrm{O}+\mathrm{O}\left({ }^{1} \mathrm{D}\right)$ \\
\hline $\mathrm{R} 12$ & $\mathrm{~N}_{2}(\mathrm{C})+\mathrm{O}_{2}=\mathrm{N}_{2}+\mathrm{O}+\mathrm{O}$ \\
\hline $\mathrm{R} 13$ & $\mathrm{e}^{-}+\mathrm{O}_{2}^{+}=\mathrm{O}+\mathrm{O}$ \\
\hline R14 & $\mathrm{N}+\mathrm{O}_{2}=\mathrm{NO}+\mathrm{O}$ \\
\hline $\mathrm{R} 15$ & $\mathrm{e}^{-}+\mathrm{CH}_{4}=\mathrm{e}^{-}+\mathrm{CH}_{3}+\mathrm{H}$ \\
\hline R16 & $\mathrm{e}^{-}+\mathrm{CH}_{4}=\mathrm{e}^{-}+\mathrm{e}^{-}+\mathrm{CH}_{3}^{+}+\mathrm{H}$ \\
\hline $\mathrm{R} 17$ & $\mathrm{~N}_{2}(\mathrm{C})+\mathrm{CH}_{4}=\mathrm{N}_{2}+\mathrm{CH}_{3}+\mathrm{H}$ \\
\hline $\mathrm{R} 18$ & $\mathrm{O}+\mathrm{OH}=\mathrm{H}+\mathrm{O}_{2}$ \\
\hline R19 & $\mathrm{O}+\mathrm{CH}_{2} \mathrm{O}=\mathrm{CO}+\mathrm{OH}+\mathrm{H}$ \\
\hline $\mathrm{R} 20$ & $\mathrm{CO}+\mathrm{OH}=\mathrm{CO}_{2}+\mathrm{H}$ \\
\hline $\mathrm{R} 21$ & $\mathrm{CH}_{3}+\mathrm{O}=\mathrm{CH}_{2} \mathrm{O}+\mathrm{H}$ \\
\hline $\mathrm{R} 22$ & $\mathrm{CH}_{3}+\mathrm{O}=\mathrm{CO}+\mathrm{H}_{2}+\mathrm{H}$ \\
\hline $\mathrm{R} 23$ & $\mathrm{e}^{-}+\mathrm{N}_{2}=\mathrm{e}^{-}+\mathrm{N}_{2}(\mathrm{~A})$ \\
\hline $\mathrm{R} 24$ & $\mathrm{~N}_{2}(\mathrm{~B})+\mathrm{N}_{2}=\mathrm{N}_{2}(\mathrm{~A})+\mathrm{N}_{2}$ \\
\hline $\mathrm{R} 25$ & $\mathrm{~N}_{2}(\mathrm{~B})+\mathrm{CH}_{4}=\mathrm{N}_{2}(\mathrm{~A})+\mathrm{CH}_{4}$ \\
\hline R26 & $\mathrm{e}^{-}+\mathrm{O}_{2}=\mathrm{e}^{-}+\mathrm{O}_{2}\left(\mathrm{a}^{1} \Delta_{\mathrm{g}}\right)$ \\
\hline $\mathrm{R} 27$ & $\mathrm{O}_{2}\left(\mathrm{~b}^{1} \Sigma_{\mathrm{g}}^{+}\right)+\mathrm{CH}_{4}=\mathrm{O}_{2}\left(\mathrm{a}^{1} \Delta_{\mathrm{g}}\right)+\mathrm{CH}_{4}$ \\
\hline
\end{tabular}

The addition of the inert gas has a crucial influence on the main generation pathway of the radicals but has little effect on the main generation pathway of the electronically excited species in the methane-air NRP discharge plasma. The main formation pathway of $\mathrm{CH}_{3}$ changes from $\mathrm{R} 4$ to $\mathrm{R} 1$, especially for the Ar-diluted methane-air plasma, with the produced values altering from $96.14 \%$ for R4 to $51.19 \%$ for R1. Similarly, the main generation pathway of $\mathrm{H}$ changes from $\mathrm{R} 22$ to $\mathrm{R} 18$, $\mathrm{R} 19$, and R21. Nevertheless, the main generation pathway of $\mathrm{N}_{2}(A)$ and $\mathrm{O}_{2}\left(\mathrm{a}^{1} \Delta_{\mathrm{g}}\right)$ has always been the electron impact excitation.

2.3. Effect of Inert Gas on the Ignition Enhancement. Figure 7 shows ignition delays in the NRP discharge plasma under three gas components at a temperature of $1330 \mathrm{~K}$ and an atmospheric pressure of 0.45 . Ignition delay is defined as the time interval from the starting point to the time when the maximum temperature rise rate is reached. "None" represents the simulation result of the GRI 3.0 methane-air combustion model without considering the plasma effect. " $\mathrm{CH}_{4}-$ Air," "HeDiluted," and "Ar-Diluted" illustrate the influence of the kinetic effect of the methane-air, He-diluted methane-air, and Ardiluted methane-air NRP discharge plasma on ignition delay, respectively. As shown in Figure 7, methane-air spontaneously ignites after $10.3 \mathrm{~ms}$ when no plasma is added under an initial temperature of $1330 \mathrm{~K}$. The kinetic effect of the methane-air plasma increases the initial density of the active species and effectively reduces the ignition delay to $8.1 \mathrm{~ms}$. Compared with the methane-air plasma, the dilution of $\mathrm{He}$ and Ar has obvious

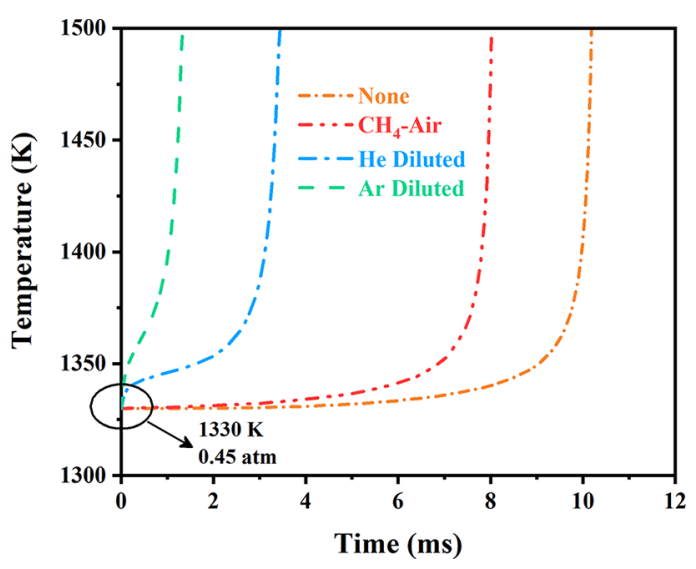

Figure 7. Ignition delays in the NRP discharge plasma under three gas components.

effects on reducing ignition delays and the ignition delays of these decreased by 58.0 and $84.0 \%$, respectively.

Figure 8 shows the reaction pathways to generate different kinds of species in the methane-air NRP discharge PAI at the moment of ignition delay. Blue line shows $\mathrm{CH}_{4} \rightarrow \mathrm{CH}_{3} \rightarrow$ $\mathrm{CH}_{3} \mathrm{O} \rightarrow \mathrm{CH}_{2} \mathrm{O} \rightarrow \mathrm{HCO} \rightarrow \mathrm{CO} \rightarrow \mathrm{CO}_{2}$, which is the significant pathway of the $\mathrm{CH}_{4}$ combustion kinetics. The most majority of $\mathrm{CH}_{4}$ reacts with $\mathrm{O}, \mathrm{OH}$, and $\mathrm{H}$ to dehydrogenate into $\mathrm{CH}_{3} \cdot \mathrm{CH}_{3} \mathrm{O}$ is mainly formed by the simultaneous chemical reactions of $\mathrm{CH}_{3}$ with $\mathrm{O}_{2}, \mathrm{H}$, and $\mathrm{HO}_{2}$. The relevant chemical reaction of $\mathrm{CH}_{3} \mathrm{OH}$, which is mainly produced by the reaction between $\mathrm{CH}_{3}$ and $\mathrm{OH}$, is also one of the important pathways to generate $\mathrm{CH}_{3} \mathrm{O} . \mathrm{CH}_{2} \mathrm{O}$ originates at 63.43, 30.41, and $3.98 \%$ from the reactions of $\mathrm{CH}_{3} \mathrm{O}$ reacting with $\mathrm{H}, \mathrm{O}_{2}$, and $\mathrm{O}$, respectively. Similarly, the species such as $\mathrm{H}, \mathrm{OH}$, and $\mathrm{O}$ are essential for the generation of $\mathrm{HCO}$ and the reaction between $\mathrm{CH}_{2}$ and $\mathrm{O}$ can provide $6 \%$ of $\mathrm{HCO}$. According to the calculation results, the contribution rate of each chemical reaction to the product changes along with the progress of combustion. Therefore, the overall pathway diagram shown in Figure 8 might no longer be applicable as the ignition is completed or $\mathrm{CH}_{4}$ is combusted.

In order to better observe the impact of the reaction rate on the PAI at specific conditions, sensitivity analysis is performed. The sensitivity is characterized by a sensitivity coefficient, which is calculated using formula $1 .^{33}$

$$
S=\frac{\tau\left(2.0 k_{l}\right)-\tau\left(0.5 k_{l}\right)}{1.5 \tau\left(k_{l}\right)}
$$

where $\tau$ is the ignition delay and $k_{l}$ is the rate coefficient of the $l$ th reaction. The negative and positive sensitivity coefficients reflect the promotion and inhabitation of the corresponding reactions on ignition enhancement, respectively.

Figure 9 shows the normalized sensitivity coefficient of the ignition delays of various reactions in "None," "methane-Air," "Ar-diluted," and "He-diluted" plasma at a temperature of 1330 $\mathrm{K}$ and an atmosphere pressure of 0.45 . The chain reactions of $\mathrm{CH}_{3}+\mathrm{O}_{2}=\mathrm{CH}_{3} \mathrm{O}+\mathrm{O}$ and $\mathrm{H}+\mathrm{O}_{2}=\mathrm{O}+\mathrm{OH}$ have high negative sensitivity coefficients for the present numerical modeling in spontaneous ignition without the effect of plasma. Simultaneously, the above reactions are also the dominant reactions in reducing the ignition delay of the methane-air PAI. The inert gas-diluted methane-air plasma has considerable influences on the normalization sensitivity, especially for $\mathrm{H}+\mathrm{O}_{2}=\mathrm{O}+\mathrm{OH}$. Reactions such as $\mathrm{OH} \rightarrow \mathrm{H}_{2} \mathrm{O}, \mathrm{HO}_{2} \rightarrow$ 


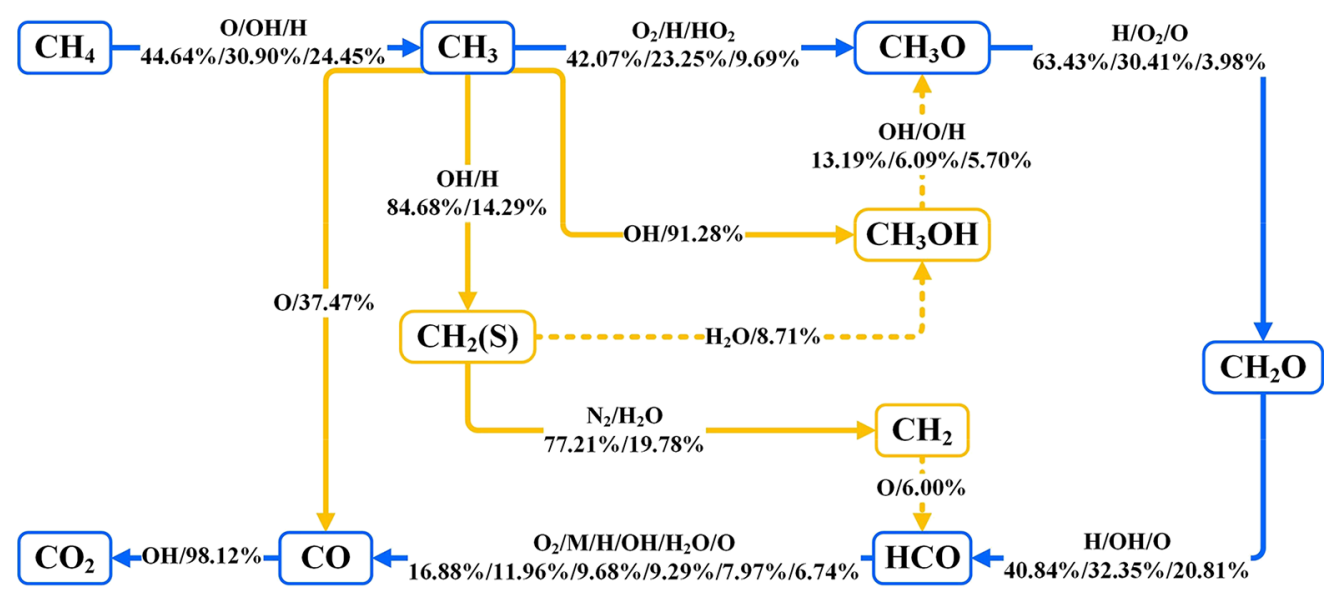

Figure 8. Reaction pathway of the methane-air NRP discharge PAI at the moment of ignition delay. The solid line and dashed line indicate the primary reaction pathways with the reaction contribution rate not less than $20 \%$ and the secondary reaction pathways with the reaction contribution rate less than $20 \%$, respectively. Blue line is the main pathway during the conversion of $\mathrm{CH}_{4}$ to $\mathrm{CO}_{2}$. Yellow line is the reaction pathway of the key intermediates formed during the conversion of $\mathrm{CH}_{4}$ to $\mathrm{CO}_{2}$.
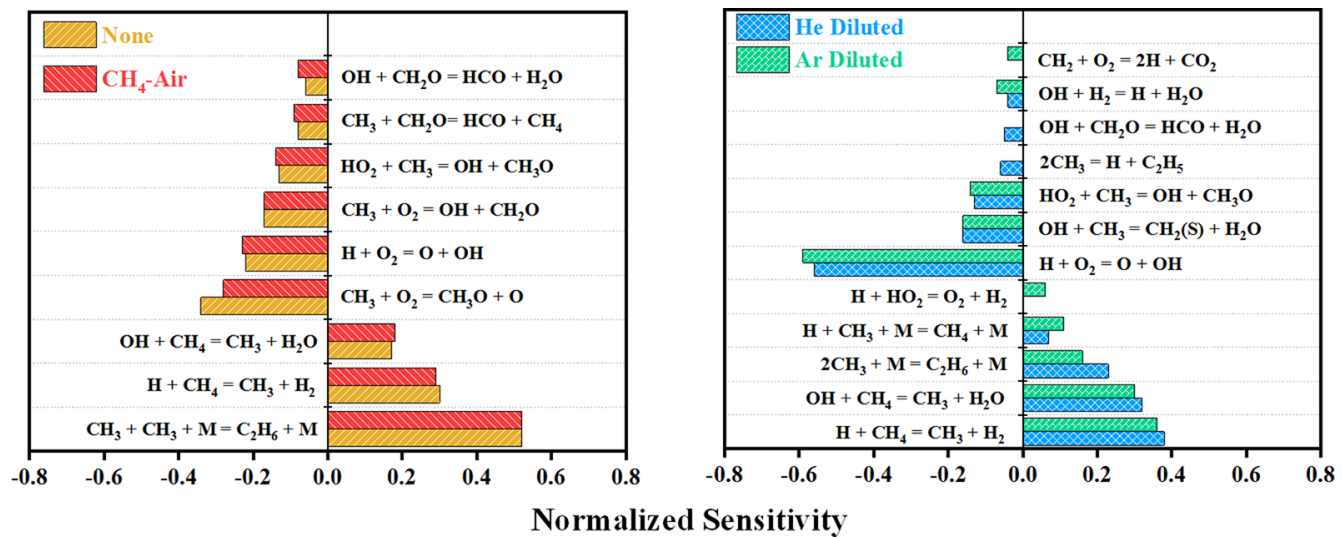

Figure 9. Normalized sensitivity coefficient of the ignition delays of various reactions.

$\mathrm{CH}_{3} \mathrm{O}, \mathrm{CH}_{2} \mathrm{O} \rightarrow \mathrm{HCO}, \mathrm{CH}_{3} \rightarrow \mathrm{C}_{2} \mathrm{H}_{5}$, and $\mathrm{CH}_{2} \rightarrow \mathrm{CO}_{2}$ have negative sensitivity coefficients, which are conduced to reduce the ignition delay and promote the ignition process. The recombination reactions of $\mathrm{CH}_{3}, \mathrm{H}+\mathrm{CH}_{4}=\mathrm{CH}_{3}+\mathrm{H}_{2}$, and $\mathrm{OH}+\mathrm{CH}_{4}=\mathrm{CH}_{3}+\mathrm{H}_{2} \mathrm{O}$ have inhibitive effects on the spontaneous ignition both with and without nonequilibrium NRP discharge plasma.

\section{CONCLUSIONS}

The global loosely coupled PAC model has been established to investigate the inert gas-diluted methane-air NRP PAI. This study gives the following important observations:

(1) The densities of the electrons, radicals, and electronically excited species in the inert gas-diluted methane-air plasma are higher than those in the methane-air plasma. The radical $\mathrm{CH}_{3}$ plays an essential role in the formation of hydrocarbons $\mathrm{C}_{x} \mathrm{H}_{y}$ $(x \leq 3), \mathrm{CH}_{2} \mathrm{O}$, and $\mathrm{CO}$ in the methane-air plasma. The addition of the inert gas has crucial influences on the main generation pathways of the radicals but has little effect on the main generation pathways of electronically excited species.

(2) The inert gas-diluted methane-air NRP discharge plasma has an obvious effect on reducing the ignition delay compared to methane-air NRP discharge plasma. The Ardiluted methane-air NRP discharge plasma has a better ignition enhancement effect than the He-diluted methane-air NRP discharge plasma.
(3) $\mathrm{CH}_{3}+\mathrm{O}_{2}=\mathrm{CH}_{3} \mathrm{O}+\mathrm{O}$ and $\mathrm{H}+\mathrm{O}_{2}=\mathrm{O}+\mathrm{OH}$ are the significant conducive reactions in the methane-air ignition chemistry. In addition, the diluted methane-air NRP discharge plasma has considerable influences on the normalization sensitivity coefficients, especially for the above two reactions. The recombination reactions of $\mathrm{CH}_{3}, \mathrm{H}+\mathrm{CH}_{4}=$ $\mathrm{CH}_{3}+\mathrm{H}_{2}$, and $\mathrm{OH}+\mathrm{CH}_{4}=\mathrm{CH}_{3}+\mathrm{H}_{2} \mathrm{O}$ have inhibitive effects on the spontaneous ignition both with and without nonequilibrium NRP discharge plasma.

\section{METHODS}

4.1. Physical Model. The model applied in the present study was developed on the basis of the model used in the previous study. ${ }^{22}$ In brief, the species densities in the plasma model and in the combustion model were solved using eqs 2 and 3 , respectively.

$$
\begin{gathered}
\frac{d N_{i}}{d t}=\sum_{j=1}^{j_{\max }} Q_{i j}(t) \\
\rho \frac{d \Upsilon_{n}}{d t}=\omega_{n} W_{n}
\end{gathered}
$$

where $N_{i}$ is the density of $i$ th species, $Q_{i j}$ is the source rate of $i$ th species related to the $j$ th reactions, $\rho$ is the gas density, $\Upsilon$ is the mass fraction of $n$th species, $\omega_{n}$ is the generation or 


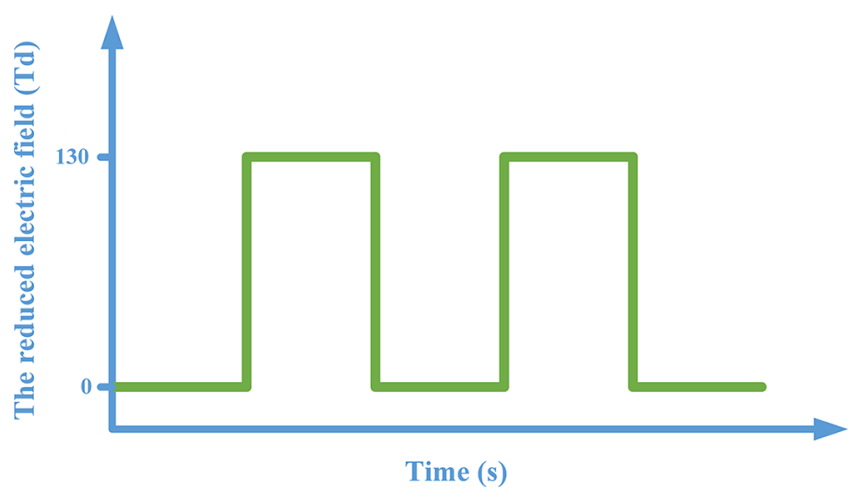

Figure 10. Schematic of $E / N$ for the NRP discharge.

consumption rate of $n$th species, and $W_{n}$ is the molecular weight of $n$th species.

The heat addition in combustion is discretized using the following equation

$$
\rho C_{\mathrm{v}} \frac{d T_{\text {gas }}}{d t}=-\sum_{n=1}^{n_{\max }} e_{n} \omega_{n} W_{n}
$$

where $C_{\mathrm{v}}$ is the specific heat of gas at a constant volume and $e_{n}$ is the internal energy for $n$th species in the mass unit.

The plasma power supply applied in this study is described by the parameter of $E / N$ with the same treatment as in ref 22, and its schematic diagram is shown in Figure 10. In one pulse period of the NRP discharge, the maximum value of $E / N$ is $130 \mathrm{Td}$, which lasted for $1 \mathrm{~ns}$ with a time step of $0.01 \mathrm{~ns}$ and then rapidly dropped to $0 \mathrm{Td}$ in the rest time with a time step of $1 \mu \mathrm{s}$. The pulse repetition frequency is $10 \mathrm{kHz}$. The pulse duration used in the simulation model is $1 \mathrm{~ns}$. The gas pressure equals to 0.45 atmospheric pressure. The simulation results such as time, temperature, and mole fraction are considered for the combustion module after 100 cycles of plasma model operation as initial values to execute the combustion model.

4.2. Chemical Model. In the present numerical modeling, the neutral species and charged species in the inert gas-diluted methane-air plasma are summarized in Table 2, which are partly the same as the species considered in the literature. ${ }^{22}$ The addition of inert gas contributes to the existence of the ground state atoms of argon and helium, the electronically excited species of argon and helium, and the positive ions of argon and helium in the inert gas-diluted methane-air plasma kinetics model. Furthermore, the reaction rate coefficients of the chemical reactions in the inert gas-diluted methane-air plasma kinetics model are calculated by BOLSIG.$+^{34,35}$

GRI $3.0^{36}$ is introduced to simulate the combustion process. Such plasma species as electronically excited species and ozone added in the GRI 3.0 are listed in Table 3.
Table 3. Plasma Species Added in the Combustion Model GRI 3.0

\begin{tabular}{c} 
plasma species \\
$\mathrm{N}_{2}(\mathrm{~A}), \mathrm{N}_{2}(\mathrm{~B}), \mathrm{N}_{2}(\mathrm{C}), \mathrm{N}_{2}\left(\mathrm{a}^{\prime}\right), \mathrm{O}\left({ }^{1} \mathrm{D}\right), \mathrm{O}_{2}\left(\mathrm{a}^{1} \Delta_{\mathrm{g}}\right), \mathrm{O}_{2}\left(\mathrm{~b}^{1} \Sigma_{\mathrm{g}}^{+}\right), \mathrm{O}_{3}$ \\
\hline
\end{tabular}

\section{ASSOCIATED CONTENT}

\section{Supporting Information}

The Supporting Information is available free of charge at https://pubs.acs.org/doi/10.1021/acsomega.1c03696.

Data of ZDPlasKin and ChemKin in the global loosely coupled PAC kinetic model (PDF)

\section{AUTHOR INFORMATION}

\section{Corresponding Author}

Jie Pan - School of Physics and Electronics, Shandong Normal University, Jinan 250014, China; 이이. orid.org/0000-00021572-1615; Email: sdnupanjie@163.com

\section{Authors}

Chengjie Bai - School of Physics and Electronics, Shandong Normal University, Jinan 250014, China

Shi Li - School of Physics and Electronics, Shandong Normal University, Jinan 250014, China

Tong Chen - School of Physics and Electronics, Shandong Normal University, Jinan 250014, China

Xiaoxiao Chen - School of Physics and Electronics, Shandong Normal University, Jinan 250014, China

Wenjing Meng - School of Physics and Electronics, Shandong Normal University, Jinan 250014, China

Complete contact information is available at:

https://pubs.acs.org/10.1021/acsomega.1c03696

\section{Author Contributions}

${ }^{\#}$ C.B., S.L., and T.C. contributed equally.

Notes

The authors declare no competing financial interest.

\section{ACKNOWLEDGMENTS}

This study was supported by the National Natural Science Foundation of China (No. 51707111 and No. 52077129) and the China Postdoctoral Science Foundation (No. 2017M612324).

\section{REFERENCES}

(1) Lyngfelt, A. Chemical looping combustion: Status and development challenges. Energy Fuel 2020, 34, 9077-9093.

(2) Liu, H.; Huang, Y.; Yuan, H.; Yin, X.; Wu, C. Life cycle assessment of biofuels in china: status and challenges. Renew. Sustain. Energy Rev. 2018, 97, 301-322.

(3) Ju, Y.; Sun, W. Plasma assisted combustion: dynamics and chemistry. Prog. Energy Combust. Sci. 2015, 48, 21-83.

(4) Zhao, Y.; Wang, C.; Li, L.; Wang, L.; Pan, J. Reaction pathways of producing and losing particles in atmospheric pressure methane

\section{Table 2. Species Included in the Plasma Kinetics Model}

\begin{tabular}{|c|c|c|}
\hline gas type & neutral species & charged species \\
\hline $\begin{array}{l}\text { methane- } \\
\text { air }\end{array}$ & $\begin{array}{l}\mathrm{H}, \mathrm{H}_{2}, \mathrm{C}, \mathrm{O}, \mathrm{O}_{2}, \mathrm{O}_{3}, \mathrm{~N}, \mathrm{~N}_{2}, \mathrm{CH}, \mathrm{CH}_{2}, \mathrm{CH}_{3}, \mathrm{CH}_{4}, \mathrm{C}_{2} \mathrm{H}_{2}, \mathrm{C}_{2} \mathrm{H}_{3}, \mathrm{C}_{2} \mathrm{H}_{4}, \mathrm{C}_{2} \mathrm{H}_{5}, \mathrm{C}_{2} \mathrm{H}_{6}, \mathrm{C}_{3} \mathrm{H}_{5}, \mathrm{C}_{3} \mathrm{H}_{6}, \mathrm{C}_{3} \mathrm{H}_{7}, \mathrm{C}_{3} \mathrm{H}_{8}, \mathrm{OH}, \mathrm{HO}_{2}, \\
\mathrm{NO}_{2}, \mathrm{NO}, \mathrm{CO}, \mathrm{CO}_{2}, \mathrm{CHO}, \mathrm{CH}_{2} \mathrm{O}, \mathrm{O}_{2}^{*}, \mathrm{O}_{2}\left(\mathrm{a}^{1} \Delta_{\mathrm{g}}\right), \mathrm{O}_{2}\left(\mathrm{~b}^{1} \Sigma_{\mathrm{g}}^{+}\right), \mathrm{O}\left({ }^{1} \mathrm{D}\right), \mathrm{N}_{2}(\mathrm{~A}), \mathrm{N}_{2}(\mathrm{~B}), \mathrm{N}_{2}\left(\mathrm{a}^{\prime}\right), \mathrm{N}_{2}(\mathrm{C})\end{array}$ & $\begin{array}{l}\mathrm{e}, \mathrm{O}_{2}^{+}, \mathrm{O}^{+}, \mathrm{O}_{2}^{-}, \mathrm{O}^{-} \\
\mathrm{N}_{2}^{+}, \mathrm{N}^{+}, \mathrm{CH}_{4}^{+}, \mathrm{CH}_{3}^{+}\end{array}$ \\
\hline argon & $\mathrm{Ar}, \mathrm{Ar}^{*}$ & $\mathrm{Ar}^{+}$ \\
\hline helium & $\mathrm{He}, \mathrm{He}^{*}$ & $\mathrm{He}^{+}$ \\
\hline
\end{tabular}


nanosecond pulsed needle-plane discharge plasma. Phys. Plasmas 2018, 25, No. 033504.

(5) Pastor-Pérez, L.; Patel, V.; Le Saché, E.; Reina, T. R. $\mathrm{CO}_{2}$ methanation in the presence of methane: Catalysts design and effect of methane concentration in the reaction mixture. J. Energy Inst. 2020, 93, 415-424.

(6) Chang, S. J. Solving the problem of carbon dioxide emissions. Forest Policy Econ. 2013, 35, 92-97.

(7) Pan, J.; Li, L. Particle densities of the pulsed dielectric barrier discharge in nitrogen at atmospheric pressure. J. Phys. D Appl. Phys. 2015, 48, No. 055204.

(8) Liu, K.; Ren, W.; Ran, C.; Zhou, R.; Tang, W.; Zhou, R.; Yang, Z.; Ostrikov, K. Long-lived species in plasma-activated water generated by an AC multi-needle-to-water discharge: effects of gas flow on chemical reactions. J. Phys. D Appl. Phys. 2021, 54, No. 065201.

(9) Bai, C.; Wang, L.; Li, L.; Dong, X.; Xiao, Q.; Liu, Z.; Sun, J.; Pan, $J$. Numerical investigation on the $\mathrm{CH}_{4} / \mathrm{CO}_{2}$ nanosecond pulsed dielectric barrier discharge plasma at atmospheric pressure. AIP Adv. 2019, 9, No. 035023.

(10) El-Shafie, M.; Kambara, S.; Hayakawa, Y. Study of the reactor temperature effect on $\mathrm{H}_{2}$ production from steamed composition using DBD plasma. Energy Rep. 2020, 6, 45-51.

(11) Zhao, Y.; Wang, C.; Wang, W.; Li, L.; Sun, H.; Shao, T.; Pan, J. Numerical simulation on particle density and reaction pathways in methane needle-plane discharge plasma at atmospheric pressure. Acta Phys. Sin. 2018, 67, No. 085202.

(12) Chen, X.; Zhang, S.; Li, S.; Zhang, C.; Pan, J.; Murphy, A. B.; Shao, T. Temperature-independent, nonoxidative methane conversion in nanosecond repetitively pulsed DBD plasma. Sustain. Energy Fuels 2021, 5, 787-800.

(13) Zhang, K.; Song, F.; Jin, D.; Xu, S.; Sun, J.; Huang, S. Experimental investigation on the cracking of pre-combustion cracking gas with gliding arc discharge plasma. Int. J. Hydrogen Energy 2021, 46, 9019-9029.

(14) Giorgi, M. G. D.; Ficarella, A.; Sciolti, A.; Pescini, E.; Campilongo, S.; Lecce, G. D. Improvement of lean flame stability of inverse methane/air diffusion flame by using coaxial dielectric plasma discharge actuators. Energy 2017, 126, 689-706.

(15) Sayed-Kassem, A.; Elorf, A.; Gillon, P.; Idir, M.; Sarh, B.; Gilard, V. Numerical modelling to study the effect of DC electric field on a laminar ethylene diffusion flame. Int. Commun. Heat Mass Transfer 2021, 122, No. 105167.

(16) Chintala, N.; Bao, A.; Lou, G.; Adamovich, I. V. Measurements of combustion efficiency in non-equilibrium RF plasma-ignited flows. Combust. Flame 2006, 144, 744-756.

(17) Bulat, M. P.; Bulat, P. V.; Denissenko, P. V.; Esakov, I. I.; Grachev, L. P.; Lavrov, P. V.; Volkov, K. N.; Volobuev, I. A. Plasmaassisted ignition and combustion of lean and rich air/fuel mixtures in low- and high-speed flows. Acta Astronaut. 2020, 176, 700-709.

(18) Pan, J.; Meng, W.; Li, S.; Du, J. Numerical investigations on methane-air nanosecond pulsed dielectric barrier discharge plasmaassisted combustion. ACS Omega 2020, 5, 31891-31901.

(19) Lefkowitz, J. K.; Guo, P.; Ombrello, T.; Won, S. H.; Stevens, C. A.; Hoke, J. L.; Schauer, F.; Ju, Y. Schlieren imaging and pulsed detonation engine testing of ignition by a nanosecond repetitively pulsed discharge. Combust. Flame 2015, 162, 2496-2507.

(20) Cont-Bernard, D. D.; Guiberti, T. F.; Lacoste, D. A. Laser induced fluorescence investigation of the chemical impact of nanosecond repetitively pulsed glow discharges on a laminar methane-air flame. Proc. Combust. Inst. 2021, 38, 6641-6649.

(21) Han, M.; Luo, Y.; Li, H.; Xu, Y.; Luo, S.; Xu, H.; Xu, C.; Li, L. Effects of the dynamic cathode sheath on electron transport at the initial period of HiPIMS pulse studied by Langmuir probe measurements and 2D PIC-MCC simulation. Surf. Coat. Technol. 2020, 403, No. 126371.

(22) Li, S.; Bai, C.; Chen, X.; Meng, W.; Li, L.; Pan, J. Numerical investigation on plasma assisted ignition of methane/air mixture excited by the synergistic nanosecond repetitive pulsed and DC discharge. J. Phys. D Appl. Phys. 2021, 54, No. 015203.

(23) Casey, T. A.; Han, J.; Belhi, M.; Arias, P. G.; Bisetti, F.; Im, H. G.; Chen, J. Y. Simulations of planar non-thermal plasma assisted ignition at atmospheric pressure. Proc. Combust. Inst. 2017, 36, 41554163.

(24) Lefkowitz, J. K.; Guo, P.; Rousso, A.; Ju, Y. Species and temperature measurements of methane oxidation in a nanosecond repetitively pulsed discharge. Phil. Trans. R. Soc. A 2015, 373, No. 20140333.

(25) Mao, X.; Chen, Q. Effects of vibrational excitation on nanosecond discharge enhanced methane-air ignition. AIAA Journal 2018, 56, 4312-4320.

(26) Aleksandrov, N. L.; Kindysheva, S. V.; Kukaev, E. N.; Starikovskaya, S. M.; Starikovskii, A. Y. Simulation of the ignition of a methane-air mixture by a high-voltage nanosecond discharge. Plasma Physics Reports 2009, 35, 867-882.

(27) Yi, W.; Liu, H.; Feng, L.; Wang, Y.; Cui, Y.; Liu, W.; Yao, M. Multiple optical diagnostics on effects of fuel properties on spray flames under oxygen-enriched conditions. Fuel 2021, 291, No. 120129.

(28) Mohammad, A.; Juhany, K. A. Insert gas dilution and temperature effects on laminar burning velocity of DME + air mixtures. Energy Fuel 2018, 32, 6347-6354.

(29) Li, S.; Zhang, Y.; Qiu, X.; Li, B.; Zhang, H. Effects of inert dilution and preheating temperature on lean flammability limit of syngas. Energy Fuel 2014, 28, 3442-3452.

(30) Sun, H.; Li, R.; Huang, M.; Li, Z.; Xu, J. Numerical simulations of the influence of inert gases $\left(\mathrm{N}_{2} / \mathrm{CO}_{2}\right)$ on combustion characteristics of laminar-premixed biosyngas flame. ACS Omega 2021, 6, 14585-14597.

(31) Liu, H.; Cui, Y.; Chen, B.; Kyritsis, D. C.; Tang, Q.; Feng, L.; Wang, Y.; Li, Z.; Geng, C.; Yao, M. Effects of flame temperature on PAHs and soot evolution in partially premixed and diffusion flames of a diesel surrogate. Energy Fuel 2019, 33, 11821-11829.

(32) Zhang, M.; Hong, W.; Xie, F.; Liu, Y.; Su, Y.; Li, X.; Liu, H.; Fang, K.; Zhu, X. Effects of diluents on cycle-by-cycle variations in a spark ignition engine fueled with methanol. Energy 2019, 182, 11321140.

(33) Starik, A. M.; Sharipov, A. S.; Titova, N. S. The effect of the vibrational excitation of molecules on the shock-induced combustion in a syngas-air mixture. Combust. Sci. Technol. 2010, 183, 75-103.

(34) Phelps, online database. www.lxcat.net (January 2, 2020).

(35) IST-Lisbon, online database. www.lxcat.net (January 2, 2020).

(36) Smith, G.; Golden, D.; Frenklach, M.; Moriarty, N.; Eiteneer, B.; Goldenberg, M.; Bowman, C.; Hanson, R.; Song, S.; Gardiner, W., Jr; Lissianski, V.; Qin, Z. GRI-Mech Version 3.0, 1999. http:// combustion.berkeley.edu/gri-mech/version30/text30.html (December, 16). 